\title{
Academic, Personal, Social, and Career Needs of Learners of Cavite State University - Laboratory Science High School: Basis for the Enhanced School Counseling Program
}

\author{
Mark Joseph A. Lorenzo \\ Cavite State University, The Philippines
}

\begin{abstract}
The study aimed to determine the academic, personal, social, and career needs of Cavite State University - Laboratory Science High School learners as perceived by the learners themselves, their parents/guardians, and teachers. Utilizing the descriptive comparative research design, this study made use of mean, standard deviation, frequency and percentage, and Kruskal-Wallis One-way Analysis of Variance to analyze the data. Results showed that the academic needs of learners focused on the need to improve the students' attitude, knowledge, and skills in studying as well as increase their awareness about venues of growth after high school. With regards to personal needs, participants perceived the need to increase learners' self-awareness and self-acceptance of their strengths and weaknesses. In terms of social needs, participants' perception centered on the need to become more aware of their household tasks and learn to relate with their family members in a better way, to boost their self-confidence and share their ideas and feelings with other people. As regards learners' career needs, participants' perceptions focused on the need to be knowledgeable on the rewards of work in their lives and the need to be assisted goal setting by helping them to discover their interests, abilities, and aptitudes. Statistical analyses revealed a significant difference in the perception of the learners themselves, their parents, and teachers on learners' academic, personal, social, and career needs. An enhanced school counseling program that should allow the learners to be exposed to school counseling activities was proposed. In lieu of the COVID-19 pandemic, this study created an action plan and implementing procedure of the enhanced school counseling program.
\end{abstract}

Keywords: Action Plan for COVID-19 Pandemic; American School Counselor Association; Counseling; Needs Assessment; Psychology; School Counseling Program 